\title{
Review on Dental Implant and Infection Management Approach
}

\author{
Ibrahim Abdulkarim Alrakkad ${ }^{1}$, Rakan Abdulkarim Alrakkad ${ }^{2 *}$, Mohammad Saud Altamimi ${ }^{2}$, Nawaf Mubarak Alshammari ${ }^{2}$, \\ Abdulrahman Abdulaziz Salem Alghuraymil ${ }^{2}$, Mohammed Alı M John ${ }^{3}$, Rua Adnan Jalal ${ }^{4}$, Sara Youssef Alsayegh ${ }^{5}$, Loulwah Linjawi ${ }^{5}$, \\ Waseem Ahmed K Otayn ${ }^{6}$, Zainab Yaseen Ahmed Alshabib ${ }^{7}$, Shahad Hassan Alharthi ${ }^{8}$
}

${ }^{1}$ Dentist, Almass dental clinic, Hail, KSA. ${ }^{2}$ Faculty of Dentistry, University of Hail, Hail, KSA. ${ }^{3}$ Faculty of Dentistry, Ibn Sina National college, Jeddah, KSA. ${ }^{4}$ Dentist, King Abdulaziz University Dental Hospital, Jeddah, KSA. ${ }^{5}$ Faculty of Dentistry, King Abdulaziz University, Jeddah, KSA. ${ }^{6}$ Dentist, Aljyreen PHC, AI Baha, KSA. ${ }^{7}$ Dentist, Primary Health Care, Hail, KSA. ${ }^{8}$ Faculty of Medicine, Dar Al Uloom University, Riyadh, KSA.

\section{Abstract}

In the past few decades, the use of dental implants for oral rehabilitation has already been proven to have overall positive long-term and shortterm results. However, there is a high chance of postoperative infection due to local environmental factors, hindering implant success. Postoperative infection must be treated as early as possible for the implant to succeed. The Medline, Pubmed, Embase, NCBI, and Cochrane databases were searched for describing the factors and ways that the implants can get infected and the treatments of implant infections. The inclusion criteria for this study encompassed articles relating to dental implants and infection. Articles that did not focus primarily on this topic were excluded. Additional publications that were referenced in these studies were also found and utilized. The focus was awarded to those studies which reported data on the type of antibiotics and surgical procedure applied to treat the infection. Current antibiotic-prescribing habits are in dire need of improvement in treating endodontic infections. As antibiotics tend to be overprescribed for endodontic infection management, it would be wise to introduce educational initiatives to encourage better, more coherent use.

Keywords: Dental implants, Early/late failure, Osseointegration, Infection

\section{INTRODUCTION}

In the past few decades, the use of dental implants for oral rehabilitation has already been proven to have overall positive long-term and short-term results $[1,2]$. As such, dental implants are a reliable therapeutic option in various scenarios necessitating restoration or replacement, such as bridge abutments, crown support, and the placement of removable dentures. However, short-term and long-term complications are likely to arise from this practice [3]. The periodontal ligament sling fibers around natural teeth run perpendicularly; the supracrestal connective tissue fibers run parallel with implants. In contrast, the arrival into the oral cavity of prosthetic replacements for teeth, including titanium implants, creates a stark difference from natural teeth in connecting to connective tissues and supporting alveolar bone. Whether or not this provides an easier route for infection than natural teeth is unknown and has yet to be determined. Osseointegrated implants, in oral implantology, are biocompatible titanium rods surgically implanted in alveolar bone, right up to their surface and without an interposed layer of soft tissue. Prosthetic and restorative fixtures such as crowns, abutments, and other supporting prostheses are then attached to the implants. A tight bond, a biological process called Osseointegration, is formed between the implant and the bone. The microbiota that colonizes implants is similar to the microbiota surrounding teeth. The subgingival bacterial species include Bacteroides forsythus, Porphyromonas gingivalis, Campylobacter gracilis, Fusobacterium nucleatum, Peptostreptococcus micros, Streptococcus intermedius, and all species associated with healthy teeth colonize the infected implants.

However, as microbial complexes differ by patients, desirable therapy must be concentrated on the specific infection. The prevalence of postoperative infections ranges from $1.6 \%$ to $11.5 \%$ and are considered a rare complication $[4,5]$ that occurs in the month after placement of a dental implant [4].

Address for correspondence: Rakan Abdulkarim Alrakkad, Faculty of Dentistry, University of Hail, Hail, KSA. rakanalrakkad@gmail.com

This is an open-access article distributed under the terms of the Creative Commons Attribution-Non Commercial-Share Alike 3.0 License, which allows others to remix, tweak, and build upon the work non commercially, as long as the author is credited and the new creations are licensed under the identical terms.

How to cite this article: Alrakkad I A, Alrakkad R A, Altamimi M S, Alshammari N M, Alghuraymil A A S, John M A M, et al. Review on Dental Implant and Infection Management Approach. Arch. Pharm. Pract. 2022;13(1):37-9. https://doi.org/10.51847/vHOoPCPEmv 
Understanding the clinical definition of Osseointegration and its histomorphometric definition is still ongoing and impacts implant survival significantly through clinical determinants [6]. Implant failure necessitates the removal of a failed implant. It is the situation in which, upon examination, the implant does not meet quantitative measurement criteria for implant survival. These criteria take many issues into accounts, such as implants indicating above $0.2 \mathrm{~mm}$ of bone loss after the first year of loading, symptomatic mobility in implants [7], and post-insertion pain. Indeed, dental implants should not be painful. As soon as primary healing is obtained, and the lack of pain under vertical or horizontal forces is a preliminary subjective criterion for implant survival, it is vital to provide sufficient preliminary implant stability for Osseointegration to be successful. Another important determinant is local bone density in the patient, which will greatly influence the stability necessary to achieve implant success. However, even though occlusal factors participate in the health of an implant, peri-implantitis and peri-implant mucositis are mostly bacterial illnesses and both present clinical similarities with periodontal diseases. There are similitudes between peri-implant illnesses and periodontal illnesses regarding bacteria, which similitudes were described by Mombelli in 1987 [8]. Peri-implant mucositis is a reversible soft tissues inflammation, the peri-implant equivalent of gingivitis, and early investigations by Berglundh et al. in 1991 [9] asserted that the peri-implant mucosa indicated equivalent responses in its resistance to bacteria as the sub-gingival sulcus. Soon afterward, studies done by Quirynen et al. (2007) [10] and Nevins and Langer (1995) [11] demonstrated that implants could be successfully utilized to rehabilitate and repair teeth that have previously had periodontitis. However, the peri-implantitis risk in patients with a periodontitis background is quadrupled in this case (odds ratio 4.7; 95\% CI 1.0-22), according to retrospective studies by Roos-Jansaker et al. (2006b) [12], Evian et al. (2004) [13] and others, and a prospective study by Karoussis et al. (2003) [14]. Systematic reviews [15], Schou, 2002 [16], Klinge et al., 2012 [17], as well as the Consensus report of the European Workshop on Periodontology [18] are all in consensus that peri-implantitis is often observed in patients with a periodontitis background.

\section{Materials and Methods}

Articles were selected from the PubMed database, and the Mesh was searched for the following key terms: (("Dental implant infection "[Mesh]) AND ("diagnosis and treatment" [Mesh]) OR (Dental implant and infection Mesh])).

The inclusion criteria for this study encompassed articles relating to dental implants and infection. Articles that did not focus primarily on this topic were excluded. Additional publications that were referenced in these studies were also found and utilized.

\section{Results ANd Discussion}

Implant failure is a possible result of infection if left untreated. Indeed, infection is the usual leading cause of complications within the preliminary healing period. Early/late mucosal dehiscence, fistulas, swelling, and suppuration are likely findings indicating implant failure. Such symptoms, if they occur early in the primary healing period, point to a far more serious issue than if they were to occur further along in the healing period as a result of the primary bone healing process disturbance that they imply, thereby jeopardizing the successful integration of the implant $[19,20]$. Redness and swelling of the surrounding tissue may or may not manifest, and pain is not often present. As long as the procedure has not resulted in more bone loss than that attributed to the remodeling, the term "Peri-implant mucositis" is utilized for the infection. This makes it comparable to gingivitis in natural teeth. As for periimplantitis, alveolar bone loss occurs around the implant and is usually well demarcated. However, bone destruction can occur without the implant showing any signs of mobility until Osseointegration has entirely failed because Osseointegration in the bottom of the implant has remained healthy. After the onset of infection, it is recommended that the patients be prescribed antibiotics for seven days (amoxicillin with potassium clavulanate or clindamycin). Systemic and local antibiotics reduce the number of anaerobic bacteria, including some periodontal pathogens, and a simultaneous improvement in aspect should follow [21]. Chlorhexidine digluconate mouthrinses should also be performed. Suppose this therapy does not control the infection. In that case, another antimicrobial must be prescribed, followed by removal of the failed implant (in case the implant had mobility and advanced bone loss). The bacterial profiles that were diagnosed in peri-implantitis induced by functional (occlusal) overloading and peri-implantitis because of infection were different, especially using direct phasecontrast microscopy and culturing [22].

The highly significant time in diagnosing if an implant will be successful is the first two years after it was placed. The general state of the affected site along the implant is likely to determine the infection's nature and results. Additionally, it is also likely that the impact of implant failure, or the effect on the denture, bridge, or supported crown, is greater than that of natural tooth loss since it leads to a quick loss of periimplant bone [8]. The extent of infection surrounding a failed implant can be severe, in some cases requiring hospitalization $[23,24]$. Several characteristics are implant failure's suspected risk factors, with which they have been associated [24]. These factors can be mechanical or anatomical, such as poor implant positioning (in a way that does not fulfill its mechanical expectations and cannot be restored) or insufficient alveolar bone height or density $[25,26]$. Particularly, poor bone quality and quantity are general factors likely to contribute to early implant failure because bone healing requires the skeletal tissues' great biological effort. Generally, a good bone quality predicts a high success rate for preserving the alveolar bone around oral implants 
[27]. Smoking is harmful to proper wound healing and will likely jeopardize the success of a bone graft and dental implant. Indeed, smokers with or without bone grafts presented a higher implant failure rate and a higher degree of postoperative complications [28].

\section{CONCLUSION}

The osseointegration process can exhibit progressive marginal loss of bone, caused by poor implant-to-bone connection, under unpleasant systemic and local conditions. Indeed, titanium and jaw bone is very different contact surface elements required to coexist; an unpleasant chronic environment, usually of a traumatic or bacterial nature, can cause tissue interface to become distressed besides the general weakening of systemic health.

Despite the high success rate, implants are known to fail. Surgical trauma, peri-operative contamination, and the absence of primary stability appear to be the main reasons for early implant failure. By opposition, occlusal overload and peri-implantitis are usually associated with late failure. Periimplantitis, an inflammatory disease affecting soft and hard tissues around a functional implant, results in rapid or gradual bone loss and likely results in osseointegration loss [29]. Bacterial infection plays the main role in the disease etiology. Clinical infection symptoms include suppuration, bleeding upon gentle probing with an instrument, hyperplastic soft tissues, gradual bone loss, and color alterations of the marginal peri-implant tissues point to an inflammatory reaction in which bone support for the implant is likely compromised or lost [30].

\section{ACKNOWLEDGMENTS: None CONFLICT OF INTEREST: None FINANCIAL SUPPORT: None ETHICS STATEMENT: None}

\section{REFERENCES}

1. Jung RE, Pjetursson BE, Glauser R, Zembic A, Zwahlen M, Lang NP. A systematic review of the 5-year survival and complication rates of implant-supported single crowns. Clin Oral Implants Res. 2008;19(2):119-30.

2. Albrektsson T, Donos N. Implant survival and complications. The Third EAO consensus conference 2012. Clin Oral Implants Res. 2012;23(Suppl 6):63-5.

3. Derks J, Tomasi C. Peri-implant health and disease. A systematic review of current epidemiology. J Clin Periodontol. 2015;42(Suppl 16): 158-71.

4. Camps-Font O, Figueiredo R, Valmaseda-Castellón E, Gay-Escoda C. Postoperative infections after dental implant placement. Implant Dent. 2015;24(6):713-9.

5. Nolan R, Kemmoona M, Polyzois I, Claffey N. The influence of prophylactic antibiotic administration on postoperative morbidity in dental implant surgery. A prospective, double-blind, randomized controlled clinical trial. Clin Oral Implants Res. 2014;25(2):252-9.

6. Albrektsson T, Zarb GA. Current interpretations of the osseointegrated response: clinical significance. Int J Prosthodont. 1993;6(2):95-105.

7. Albrektsson T, Zarb G, Worthington P, Eriksson AR. The long-term efficacy of currently used dental implants. A review and proposed criteria of success. Int J Oral Maxillofac Implants. 1986;1(1):11-25.
8. Mombelli A, Décaillet F. The characteristics of biofilms in peri-implant disease. J Clin Periodontol 2011;38(Suppl. 11):203-13. doi:10.1111/j.1600-051X.2010.01666.x.

9. Berglundh T, Lindhe J, Ericsson I, Marinello CP, Liljenberg B, Thomsen P. The soft tissue barrier at implants and teeth. Clin Oral Implants Res. 1991;2(2):81-90. doi:10.1034/j.16000501.1991.020206.x

10. Alsaadi G, Quirynen M, Komárek A, van Steenberghe D. Impact of local and systemic factors on the incidence of oral implant failures, up to abutment connection. J Clin Periodontol. 2007;34(7):610-7. doi:10.1111/j.1600-051X.2007.01077.x.

11. Nevins M, Langer B. The successful application of osseointegrated implants to the posterior jaw: a long-term retrospective study. Int J Oral Maxillofac Implants. 1993;8(4):428-32.

12. Roos-Jansåker AM, Renvert H, Lindahl C, Renvert S. Nine-to fourteen-year follow-up of implant treatment. Part III: factors associated with peri-implant lesions. J Clin Periodontol. 2006;33(4):296-301.

13. Evian CI, Emling R, Rosenberg ES, Waasdorp JA, Halpern W, Shah S, et al. Retrospective analysis of implant survival and the influence of periodontal disease and immediate placement on long-term results. Int J Oral Maxillofac Implants. 2004;19(3).

14. Karoussis IK, Salvi GE, Heitz-Mayfield LJ, Brägger U, Hämmerle CH, Lang NP. Long-term implant prognosis in patients with and without a history of chronic periodontitis: a 10-year prospective cohort study of the ITI Dental Implant System. Clin Oral Implants Res. 2003;14(3):329-39. doi:10.1034/j.1600-0501.000.00934.x.

15. Klokkevold PR, Han TJ. How do smoking, diabetes, and periodontitis affect outcomes of implant treatment?. Int J Oral Maxillofac Implants. 2007;22(7):173-205.

16. Schou S, Holmstrup P, Stoltze K, Hjørting-Hansen E, Fiehn NE, Skovgaard LT. Probing around implants and teeth with healthy or inflamed peri-implant mucosa/gingiva. A histologic comparison in cynomolgus monkeys (Macaca fascicularis). Clin Oral Implants Res. 2002;13(2):113-26.

17. Klinge B, Meyle J, Working Group 2. Peri-implant tissue destruction. The Third EAO Consensus Conference 2012. Clin Oral Implants Res. 2012;23(Suppl. 6):108-10.

18. Lang NP, Berglundh T, Working Group 4 of Seventh European Workshop on Periodontology. Peri-implant diseases: where are we now?--Consensus of the Seventh European Workshop on Periodontology. J Clin Periodontol. 2011;38(Suppl 11):178-81. doi:10.1111/j.1600-051X.2010.01674.x.

19. Sakka S, Coulthard P. Implant failure: etiology and complications. Med Oral Patol Oral Cir Bucal. 2011;16:e42-4.

20. Hamed MT, Mously HA. Investigating Economic and Clinical Implications of Tooth Implant Supported Prosthesis among Patients and Practitioners. Int J Pharm Res Allied Sci. 2019;8(4):116-21.

21. Lindhe J, Berglundh T, Ericsson I, Liljenberg B, Marinello C. Experimental breakdown of peri-implant and periodontal tissues: a study in the beagle dog. Clin Oral Implants Res. 1992;3(1):9-16.

22. Rosenberg ES, Torosian JP, Slots J. Microbial differences in 2 clinically distinct types of failures of osseointegrated implants. Clin Oral Implants Res. 1991;2(3):135-44.

23. Lindhe J, Berglundh T, Ericsson I, Liljenberg B, Marinello C. Experimental breakdown of peri-implant and periodontal tissues: a study in the beagle dog. Clin Oral Implants Res. 1992;3(1):9-16.

24. Haanaes HR. Implants and infections with special reference to oral bacteria Summary [review]. J Clin Periodontol. 1990;17(Pt 2):516-24.

25. Passariello C, Berlutti F, Selan L, Amodeo C, Comodi-Ballanti MR, Serafino L, et al. Microbiological and morphological analysis of dental implants removed for incomplete osseointegration. Microb Ecol Health Dis. 1993;6(4):203-7.

26. Tonetti MS, Schmid J. Pathogenesis of implant failures. Periodontology. 2000. 1994;4(1):127-38.

27. Sakka S, Coulthard P. Bone quality: a reality for the process of osseointegration. Implant Dent. 2009;18(6):480-5.

28. Levin L, Schwartz-Arad D. The effect of cigarette smoking on dental implants and related surgery. Implant Dent. 2005;14(4):357-63.

29. Klinge B, Hultin M, Berglundh T. Peri-implantitis. Dent Clin North Am. 2005;49(3):661-76.

30. Sanchez-Garces MA, Gay-Escoda C. Periimplantitis. Med Oral Patol Oral Cir Bucal. 2004;9(Suppl 69-74):63-9. 